Article

\title{
The Protective Effect of Trichoderma asperellum on Tomato Plants against Fusarium oxysporum and Botrytis cinerea Diseases Involves Inhibition of Reactive Oxygen Species Production
}

\author{
Verónica I. Herrera-Téllez ${ }^{1}$, Ana K. Cruz-Olmedo ${ }^{2}$, Javier Plasencia ${ }^{3}{ }^{\circledR}$, Marina Gavilanes-Ruíz ${ }^{3}$, \\ Oscar Arce-Cervantes ${ }^{4}$, Sergio Hernández-León ${ }^{4}$ and Mariana Saucedo-García ${ }^{4, *}$ \\ 1 Instituto de Ciencias Básicas e Ingeniería, Universidad Autónoma del Estado de Hidalgo, \\ Pachuca-Tulancingo de Bravo Kilómetro 4.5, Mineral de la Reforma 42184, Hidalgo, Mexico; \\ iran.poxi@gmail.com \\ 2 Instituto Tecnológico de Acapulco, Carr. Cayaco Puerto Marqués s/n, Del PRI, Acapulco 39905, Guerrero, \\ Mexico; karen_link_94@hotmail.com \\ 3 Departamento de Bioquímica, Facultad de Química, Universidad Nacional Autónoma de México, \\ Mexico City 04510, Mexico; javierp@unam.mx (J.P.); gavilan@unam.mx (M.G.-R.) \\ 4 Instituto de Ciencias Agropecuarias, Universidad Autónoma del Estado de Hidalgo, Avenida Universidad \\ Km. 1, Rancho Universitario, Tulancingo-Santiago Tulantepec, Tulancingo 43600, Hidalgo, Mexico; \\ oarce@uaeh.edu.mx (O.A.-C.); sergio_hernandez@uaeh.edu.mx (S.H.-L.) \\ * Correspondence: saucedo@uaeh.edu.mx
}

Received: 28 March 2019; Accepted: 17 April 2019; Published: 24 April 2019

\begin{abstract}
Trichoderma species are fungi widely employed as plant-growth-promoting agents and for biological control. Several commercial and laboratory-made solid formulations for mass production of Trichoderma have been reported. In this study, we evaluated a solid kaolin-based formulation to promote the absortion/retention of Trichoderma asperellum in the substrate for growing tomato plants. The unique implementation of this solid formulation resulted in an increased growth of the tomato plants, both in roots and shoots after 40 days of its application. Plants were challenged with two fungal pathogens, Fusarium oxysporum and Botrytis cinerea, and pretreatment with T. asperellum resulted in less severe wilting and stunting symptoms than non-treated plants. Treatment with T. asperellum formulation inhibited Reactive Oxygen Species (ROS) production in response to the pathogens in comparison to plants that were only challenged with both pathogens. These results suggest that decrease in ROS levels contribute to the protective effects exerted by T. asperellum in tomato.
\end{abstract}

Keywords: Trichoderma asperellum; reactive oxygen species; kaolin; Fusarium oxysporum; Botrytis cinerea

\section{Introduction}

One goal of modern agriculture is the production of safe food through sustainable and eco-friendly practices. These involve a cutback in the use of chemicals in the fields to reduce potential environmental damage. In this regard, biological agents constitute an excellent alternative to replace chemicals for pest control or growth improvement. Trichoderma species are widely used for field application as biofungicides against pathogens such as Botrytis cinerea, Fusarium spp., Pythium spp., Rhizoctonia solani and Sclerotium rolfsii on crops of economic importance [1,2].

Trichoderma is a ubiquitous genus of filamentous fungi that growths in the rhizosphere and colonize plant roots as an opportunistic, avirulent plant symbiont [3]. Trichoderma spp. receives nutrients from root exudates in exchange for plant protection against biotic and abiotic stresses [4]. The interface between Trichoderma and plant is established by early events that include the release of elicitors from 
the cell walls from both organisms and the secretion of low molecular weight compounds, peptides and proteins from the fungus, leading to the recognition by the plant [5]. This first contact activates plant defense responses that promote disease resistance.

Several modes of action have been described to explain Trichoderma antagonism toward fungal pathogens and include mycoparasitism, antibiotic production and competition for nutrients [6]. Moreover, Trichoderma also exerts an indirect control against pathogens through the induced systemic response (ISR) in plant cells that results in an enhanced defense. The first evidence of induced resistance by Trichoderma was provided by Bigirimana et al. [7], who detected that soil inoculation with T. harzianum strain T-39 induced resistance to diseases caused by B. cinerea and Colletotrichum lindemuthianum in bean leaves. Systemic acquired resistance (SAR) and ISR are two forms of induced resistance, wherein plant defenses are preconditioned by prior infection or treatment that results in resistance against subsequent challenge by a pathogen or parasite [8]. ISR is activated mostly against necrotrophic pathogens, is mediated through the jasmonate (JA) and ethylene (ET) pathways, and goes without pathogenesis-related proteins (PRP) accumulation $[9,10]$. On the other hand, SAR is triggered by local infection and involves salicylic acid (SA) signaling pathway, requires PRP and is mostly effective against biotrophic and hemibiotrophic pathogens [11].

The effectiveness of microorganisms used as biocontrol agents depends on elements including environmental factors, survival in the soil, the formulation quality and the application protocol. Bacterial and fungal cells may be immobilized in solid carriers such as kaolin for preservation and protection from the external environment [12-15]. Kaolin is an inexpensive clay that essentially consists of minerals of kaolinite (ideal formula, $\left.\mathrm{Al}_{4}\left(\mathrm{Si}_{4} \mathrm{O}_{10}\right)(\mathrm{OH})_{8}\right)$ group.). It is a unique industrial mineral because is chemically inert over a relatively wide $\mathrm{pH}$ range, is white, has good covering or shielding capacity when used as a pigment, coating film or filling material, and is soft and nonabrasive [16]. Kaolin has been used to carry and preserve fungi [12,14,15,17-20] and bacteria [20-22] with herbicide activities. In addition, kaolin has also been used in formulations to produce entomopathogenic nematodes [23].

Tomato is the highest top-ranked vegetable grown over the world. It accounts for more than $15 \%$ of global vegetable production (over 177 million metric tons in 2016; www.fao.org/faostat) [24]. Diseases are a major limiting factor for tomato production, and among them, fungal diseases are quite severe. Fusarium oxysporum is a soil-borne, hemibiotrophic, fungal pathogen that reduces the productivity of tomato crops in greenhouse and field. The fungal pathogen reaches the xylem vessels in the late stages of infection inducing progressive wilting and eventually plant death [25]. Chemical methods used to control soil-borne pathogens include biocide application; however, this practice is environmentally hazardous, and some chemicals have been phased out of use [26]. Host resistance and biocontrol agents are replacing these traditional pest management practices [27].

$B$. cinerea is a necrotrophic pathogen with a wide host-range that colonizes senescent or dead dicot plant tissues and fruits to produce gray mold. Botrytis species attack nursery plants, vegetables, ornamental, field and orchard crops, as well as stored and transported agricultural products [28]. Control of $B$. cinerea is difficult due of its several attack modes, diverse hosts and inoculum sources, and because it can survive as mycelia and/or conidia for extended periods as sclerotia in crop debris. Several fungicides have been employed to control Botrytis diseases. However, resistance to cyprodinil and fludioxonil occurs in strains of this species [29]. Moreover, the current cost of releasing a new fungicide or biological control agent to the market is so high that only major crops attract sufficient interest by agribusiness [30].

A T. harzianum formulation based on solid bentonite-vermiculite is effective for controlling Fusarium wilt and promoting melon growth in greenhouse conditions [31]. This formulation has also been used in tomato plants [32]. In this work, we prepared a T. asperellum formulation using kaolin instead bentonite and analyzed its efficiency in controlling F. oxysporum or B. cinerea infections in tomato plants. Such formulation notably reduced disease progression against both fungal pathogens. 
Moreover, we found that T. asperellum prevented ROS generation. These low ROS levels were associated with disease control promoted by T. asperellum.

\section{Results}

\subsection{Kaolin Formulation Allows Trichoderma Asperellum High Biomass, Viability and Stability}

Trichoderma produces large amounts of fungal spores and this characteristic makes it ideal for inoculum production under laboratory conditions. In this study, we used a solid formulation devised to promote Trichoderma proliferation and survival in soil. The solid formulation consisted of an oat flakes/kaolin-vermiculite mixture that functions as an inexpensive, simple and readily available source of nutrients.

To evaluate T. asperellum spore viability in the growing substrate, CFUs were quantified several days after application. As shown in Figure 1, approximately $1 \times 10^{7} \mathrm{CFU} / \mathrm{g}$ soil remained at $4 \mathrm{dpi}$, and those levels were maintained throughout the experiment (40 days), indicating an optimal retention and survival of T. asperellum in the solid matrix. Moreover, this formulation showed a ten-fold higher biomass production of Trichoderma inoculum than the bentonite-vermiculite formulation employed with T. harzianum [31]. A possible explanation for this logarithmical difference may be due to the formulation $\mathrm{pH}$. According to Singh [33], T. asperellum produces high biomass at $\mathrm{pH} 7.0$ with a slow preference at $\mathrm{pH}$ 5.5. In our study, the $\mathrm{pH}$ recorded in the kaolin was 5.9, suggesting that an acidic milieu positively influences spore production.

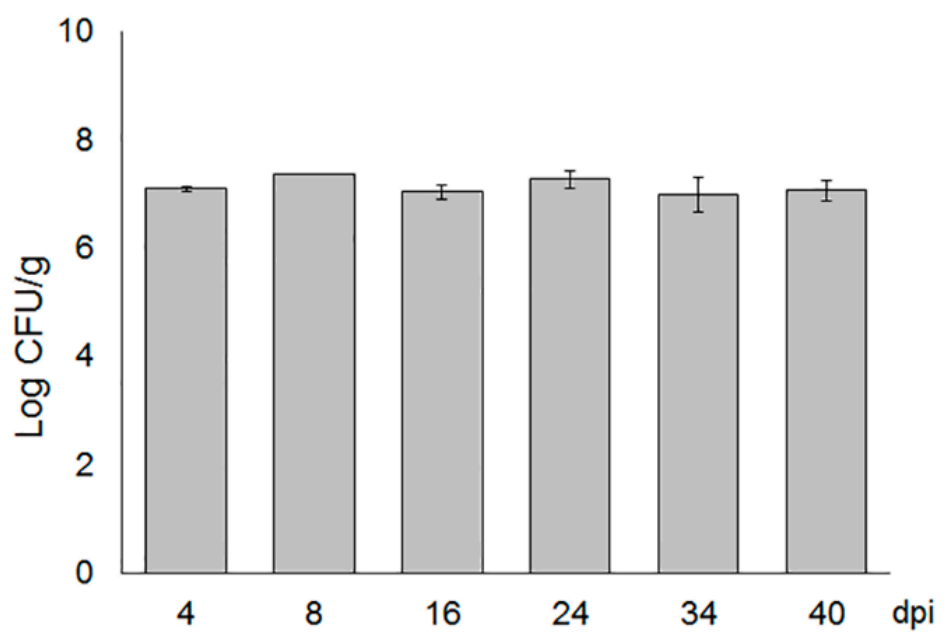

Figure 1. Trichoderma asperellum viability in the growing media. T. asperellum CFU per gram was quantified at various times after mixing with the growing substrate. The population was expressed as Log CFU/gram- Bars indicated SD from three independent experiments.

\subsection{Trichoderma Asperellum Stimulates Plant Growth on Tomato Plants}

To characterize the effect of T. asperellum on plant growth and development, two-week-old tomato seedlings were grown in sterile soil or in T. asperellum-treated soil mixes. After 40 days, growth parameters were measured. Plant absolute growth rate and chlorophyll content were $22 \%$ and $16 \%$ higher, respectively in T. asperellum-treated plants than in control plants (Table 1). Both fresh and dry weight were $30 \%$ higher in treated plants, as well. Leaf area was not significantly different between the two treatments (Table 1). 
Table 1. Effect of T. asperellum on plant growth of tomato plants. Absolute growth rate, leaf area, SPAD units, fresh and dry weight of tomato plants after 40 days of T. asperellum inoculation are shown.

\begin{tabular}{cccccc}
\hline Treatments & AGR $^{*}(\mathbf{c m} /$ day $)$ & Leaf Area $\left(\mathbf{c m}^{2}\right)$ & SPAD Units & Fresh Weight $(g)$ & Dry Weight $(\mathbf{g})$ \\
\hline Control & $0.394 \pm 0.05^{\mathrm{a}}$ & $10.91 \pm 3.00^{\mathrm{a}}$ & $22.46 \pm 1.84^{\mathrm{a}}$ & $12.72 \pm 1.38^{\mathrm{a}}$ & $0.957 \pm 0.01^{\mathrm{a}}$ \\
\hline T. asperellum & $0.50 \pm 0.08^{\mathrm{b}}$ & $12.20 \pm 2.90^{\mathrm{a}}$ & $26.75 \pm 2.09^{\mathrm{b}}$ & $18.83 \pm 0.58^{\mathrm{b}}$ & $1.38 \pm 0.01^{\mathrm{b}}$ \\
\hline
\end{tabular}

Data are means \pm S.D. from ten biological replicates. Same letter in the column denote no significant difference between both treatments according a pairwise comparison using Student's $t$-test $(p<0.05)$. ${ }^{*}$ Based on plant height.

\subsection{Trichoderma Asperellum Reduces Fusarium Oxysporum Wilt Symptoms in Tomato Plants}

The effectiveness of $T$. asperellum as a biocontrol agent was evaluated by recording the disease symptoms induced by F. oxysporum (Figure 2). Two-week-old plants were planted in the T. asperellum-solid formulation or mock, and three weeks after were inoculated with F. oxysporum. The plants were grown for three weeks post-inoculation (wpi) before disease symptoms assessment. Less severe disease symptoms caused by F. oxysporum were recorded in T. asperellum-inoculated plants than in untreated plants. Symptoms included wilting and stunting (Figure 2A). This result was concordant with the reduction in fresh-weight loss triggered by fungal pathogen infection in T. asperellum-inoculated plants in reference to non-pretreated plants (Figure 2B).

Disease severity was estimated according to leaf damage established by the scale shown in Figure 2C (upper panel) for plants after one and three weeks of infection with Fusarium. While plants infected with F. oxysporum mainly exhibited the most severe symptoms, after 3 weeks, T. asperellum-treated plants and infected with F. oxysporum displayed disease severity values averaging between one and two. These results support the role of T. asperellum as a successful biocontrol agent against Fusarium wilt.

F. oxysporum plant colonization was analyzed by cutting stem sections from different nodes of non- and pretreated plants and plated on PDA [34].

As it is shown in Figure 2D, F. oxysporum colonized cotyledon node and first node of mock plants. In a similar way, F. oxysporum was detected in the same nodes of T. asperellum-pretreated plants. However, the biocontrol agent showed faster growth. This result contrasts with the report by Martínez-Medina et al. [32] who did not detect Trichoderma presence in the shoots of tomato plants inoculated in the roots. In this regard, a possible contamination cannot be ruled out but neither that T. asperellum can be translocated through the vascular system. 

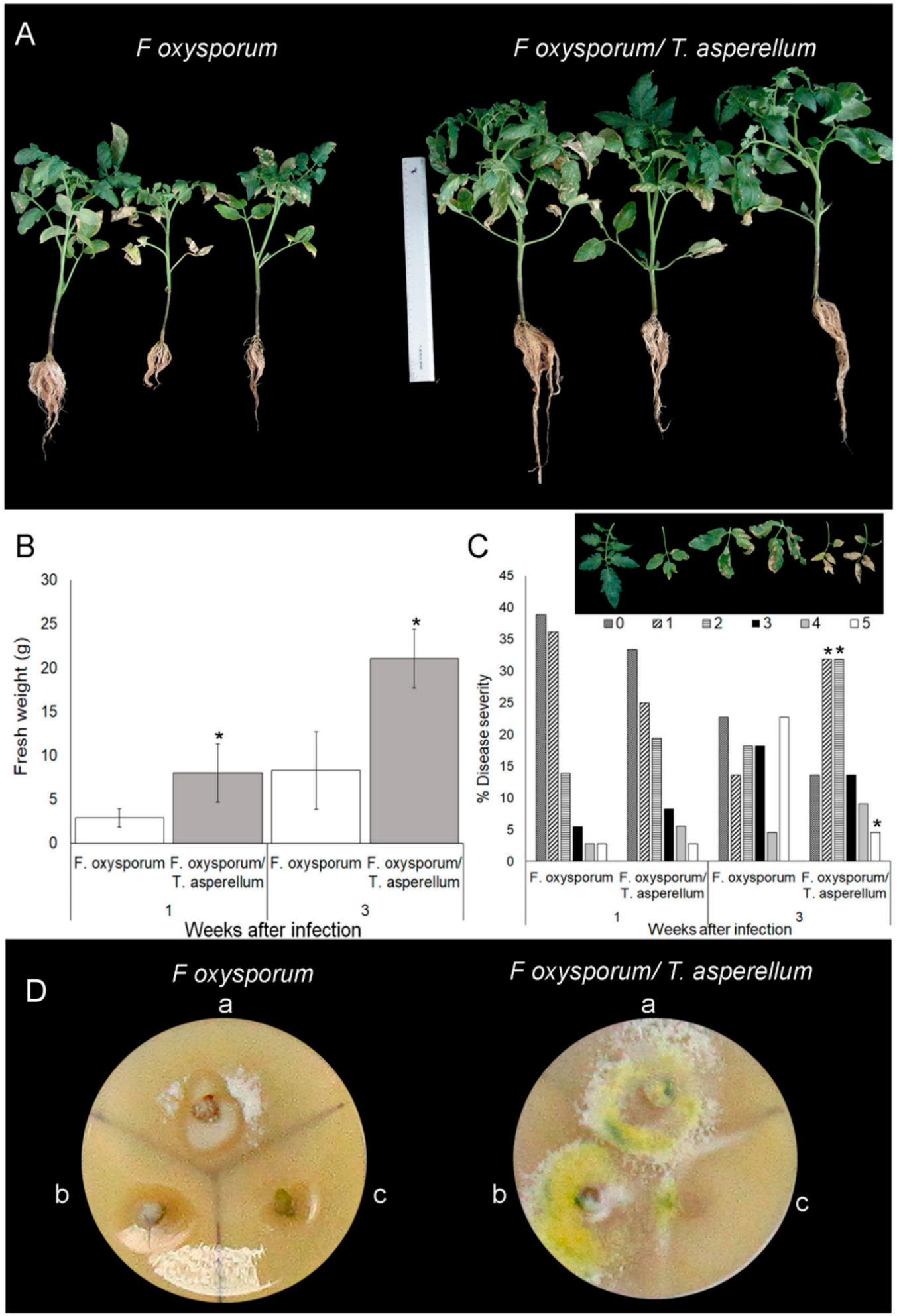

Figure 2. Trichoderma asperellum reduces Fusarium severity on tomato plants. (A) Fusarium oxysporum wilt and stunting symptoms on T. asperellum non- and preinoculated tomato plants after 3 weeks post infection. (B) Fresh weight was recorded at 1 and 3 weeks post-inoculation. (C) Disease severity (\%) scores represent the number of leaves showing different levels of wilt symptoms shown in the upper panel in reference of total number of leaves of each plant. Symptoms were recorded at 1 and 3 weeks after infection. (D) Stem section were cut from cotyledon node (a), second node (b) and third node (c) of individual tomato plants non- and preinoculated with T. asperellum and infected after 3 weeks. Photographs were taken 5 days after incubation of nodes on PDA. Asterisks indicate significant differences among treatments at a given time $(p \leq 0.05)$, error bars indicate SEM. 


\subsection{Trichoderma Asperellum Induces Systemic Resistance against Botrytis Cinerea}

To investigate the protective systemic effects of T. asperellum against fungal disease, detached leaves from mock and pretreated T. asperellum plants were inoculated with B. cinerea. Lesion development was recorded two weeks after infection. Detached leaves from T. asperellum-pretreated plants showed lower and less severe lesions compared to non-treated plants (Figure 3A,B). These results are in accordance with Martínez-Medina [32], who found a 30\% decrease in lesion size in plants inoculated with $T$. harzianum and infected by B. cinerea.

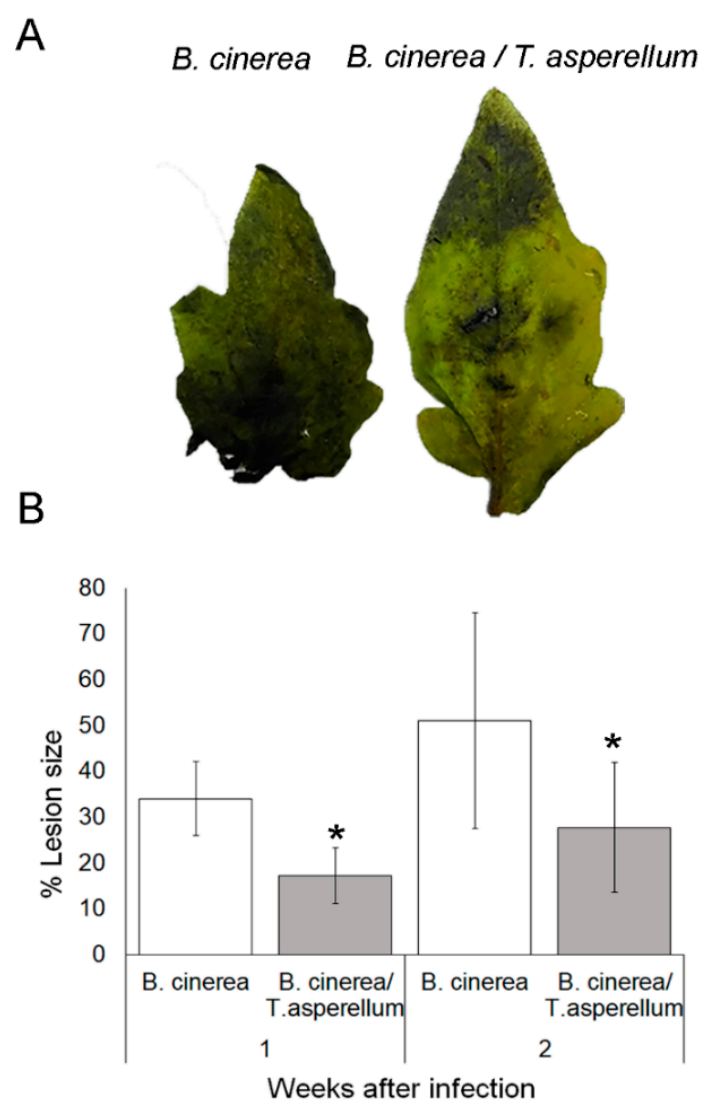

Figure 3. Trichoderma asperellum reduces Botrytis severity on tomato plants. (A) Detached leaves from non- and inoculated plants with T. asperellum were infected with $5 \mathrm{~mm}$-diameter plugs of B. cinerea. Photographs were taken two weeks after infection. (B) Lesions were measured using Image J software 1 and 2 weeks after Botrytis infection. Asterisks indicate significant differences among treatments at a given time $(p \leq 0.05)$, error bars indicate SEM.

\subsection{Trichoderma Asperellum Supresses ROS Production against Necrotrophic Pathogens}

ROS production is an early event during plant defense responses triggered by pathogens attack. In this context, the effect of T. asperellum on ROS accumulation was investigated in tomato leaves infected with F. oxysporum and B. cinerea in the first $24 \mathrm{~h}$ (Figure 4A,B, respectively). ROS production was recorded three weeks after inoculation of tomato plants with T. asperellum. 
A

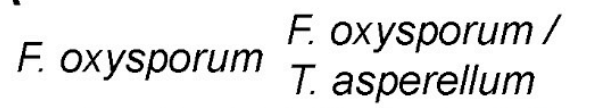

B

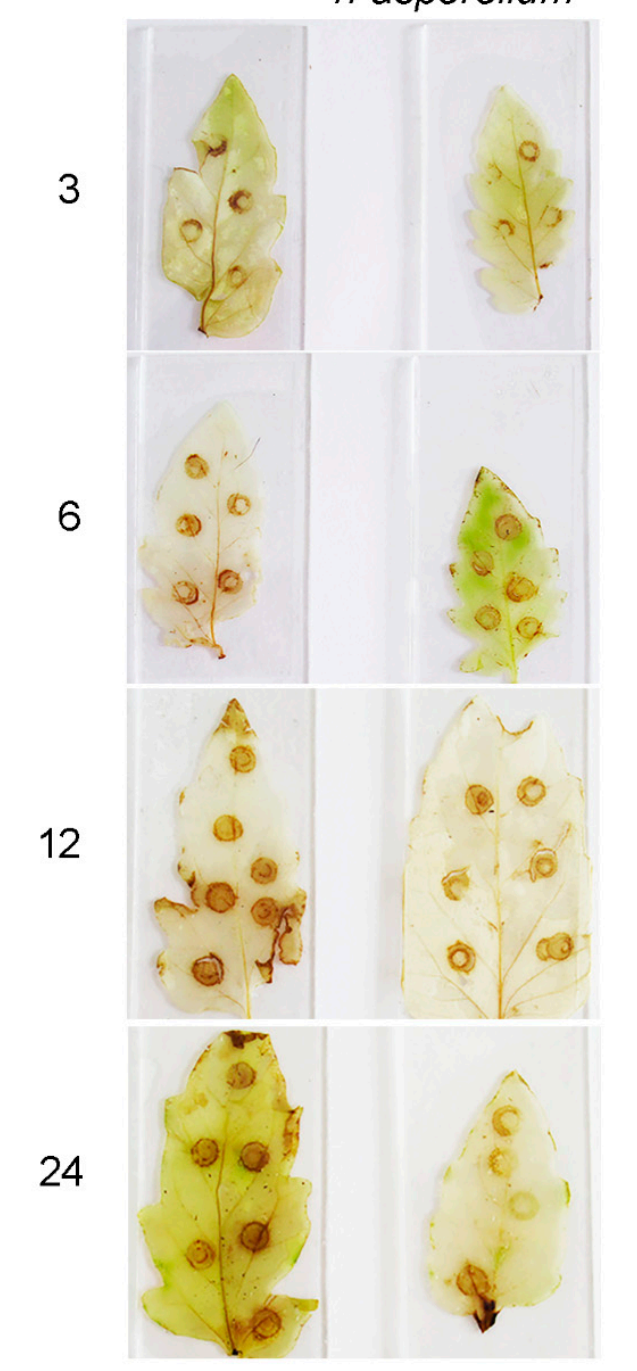

\section{Botrytis cinerea / T. asperellum}
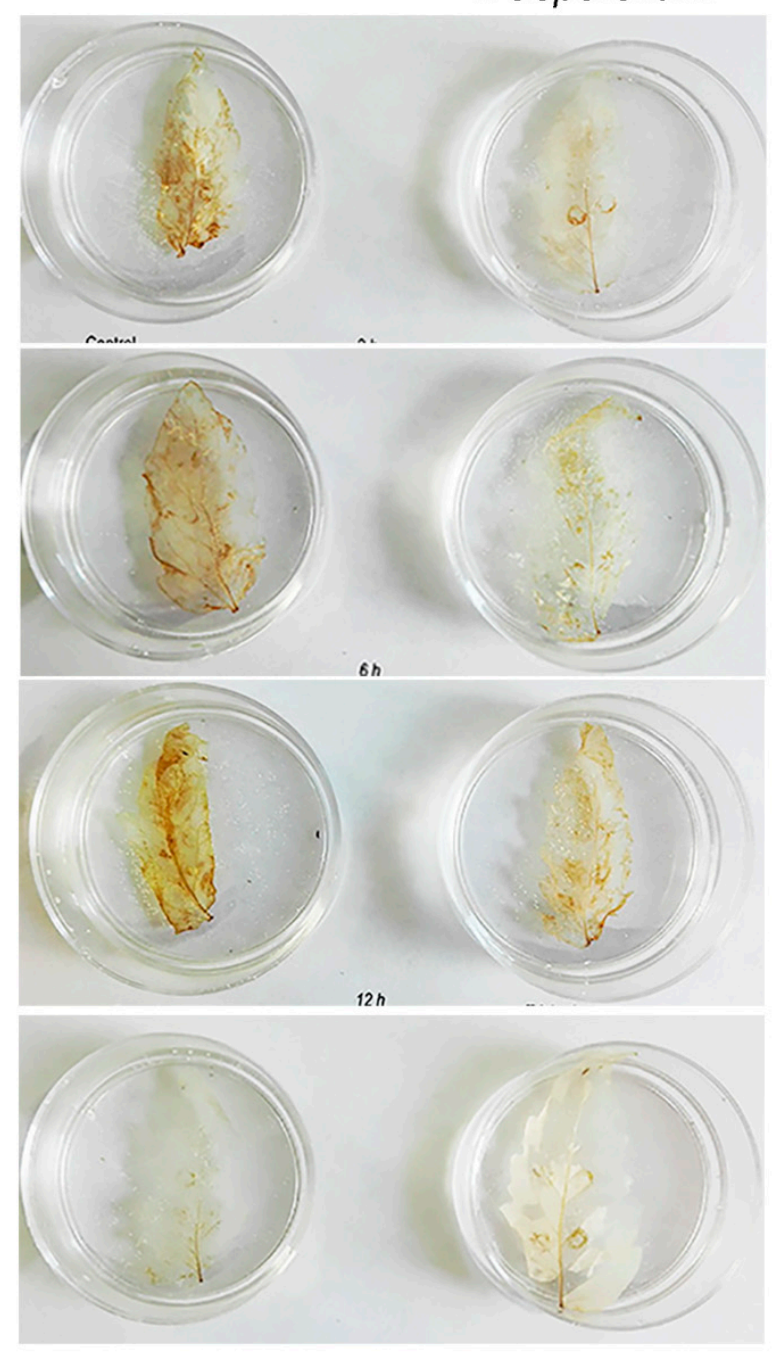

Figure 4. T. asperellum prevents ROS accumulation in response to Fusarium and Botrytis infection on tomato plants. Non- and pretreated tomato plants with T. asperellum were inoculated with $F$. oxysporum (A) or B. cinerea (B), and leaves were stained at different time periods (3, 6, 12 and $24 \mathrm{~h})$ with DAB. Infection with Fusarium was in full plants while infection of Botrytis was in detached leaves. The experiments were repeated twice.

As Figure 4 shows, ROS production was markedly diminished in tomato plants preinoculated with T. asperellum in comparison to non-treated plants infected with both fungal pathogens. ROS production was detected at $3 \mathrm{hpi}$, and it was sustained until $24 \mathrm{~h}$ and $12 \mathrm{~h}$ in plants infected with F. oxysporum and B. cinerea, respectively.

\section{Discussion}

We found that an oat/kaolin-vermiculite-based formulation for T. asperellum application was highly effective for sustaining the biocontrol agent and to protect tomato plants from F. oxysporum and B. cinerea. This protective effect was associated with the reduction of ROS production in response to pathogen infection. Under these conditions, where grinding or extrusion of bioformulation were not considered, T. asperellum viable biomass, determined as CFUs, remained unchanged over 40 days and no contamination was detected in the culture examinations, indicating that kaolin was not a source of 
contaminants, as it was previously reported [12]. Moreover, T. asperellum retained its physiological and biochemical activities in the solid formulation since its application to tomato plants led to enhanced growth and tolerance against pathogens.

Many reports have shown that Trichoderma spp. improves the growth in many plant species [11]. In this study, we demonstrated that $T$. asperellum improved plant growth parameters including plant absolute growth rate, and fresh and dry weight with a significant difference relative to mock treatment, except leaf size. It is important to highlight the enhancement of shoot and root growth as it has been reported $[35,36]$.

Chlorophyll content was also increased in T. asperellum-treated plants as was observed in melon and cacao plants inoculated with T. harzianum and T. asperellum, respectively [31,37]. This result suggests an optimal physiological status of plants.

Besides its plant growth stimulatory activity, Trichoderma spp. are fungi that reduce negative effects by plant pathogens. In our study, we investigated the suppressive role of $T$. asperellum against two fungal pathogens of tomato plants. T. asperellum reduced disease symptoms development upon infection or F. oxysporum or B. cinerea in tomato plants.

It has recently been reported that SA and JA are involved in $T$. virens-mediated resistance in tomato against $F$. oxysporum. Jasmonic acid-deficient $d e f-1$ and salicylic acid-deficient $N a h G$ mutants are more susceptible to infection. Measurement of JA in wild type plants revealed that $T$. virens cultured on barley grains or the combination T. virens plus F. oxysporum showed higher JA levels and lower disease incidence. By comparison, F. oxysporum-treated plants only showed a small increase in the JA levels [38]. These results suggest that $T$. virens is the responsible agent to induce JA changes in the plant like a defense mechanism. In contrast, SA content increased in response to the pathogen. However, SA was only slightly built up in plants treated with $T$. virens cultured on barley grains or in the combination of T. virens plus F. oxysporum [38]. The involvement of JA and SA has also been demonstrated in the resistance mediated by T. harzianum of tomato plants against $B$. cinerea. The resistance promoted by T. harzianum is also lost in def-1 and NahG mutants. In addition, def-1 mutants showed higher colonization of B. cinerea in comparison of wild type infected plants [32], suggesting that JA is controlling the pathogen proliferation in the plant tissues.

The protection mediated by T. asperellum against both pathogenic infections could be related to growth promotion, at least in part. However, in this study we report that T. asperellum inhibited ROS the common production upon pathogen infection. To avoid oxidative stress, the cells use a radical scavenging mechanism to neutralize free radicals or reactive species. Superoxide dismutase (SOD) is an enzyme whose activity is involved in the earliest defense responses. It is considered the first detoxifying line. SOD catalyzes the dismutation of superoxide anion to hydrogen peroxide [39]. T. harzianum has been shown to increase SOD activity in tomato plants after F. oxysporum infection [40]. Nevertheless, we only detected a weak $\mathrm{H}_{2} \mathrm{O}_{2}$ accumulation in the tomato leaves of plants pretreated with T.asperellum, which were subsequently pathogen-infected with reference to unpretreated plants challenged with the pathogen. According to Zehra et al. [40], the pretreatment of tomato plants with T. harzianum supresses ROS builds up by enhancing mechanisms such as antioxidant defense mediated by catalase and ascorbate peroxidase activities in response to F. oxysporum infection.

B. cinerea secretes toxins to kill plant cells. The most known are botrydial and its by-products and botcinic acid derivatives [41,42]. Besides these toxins, B. cinerea itself produces ROS in the plant during the infection process as a virulence factor. $\mathrm{H}_{2} \mathrm{O}_{2}$ accumulates in the early steps of infection, both in germinating spores and in the infection cushions [43]. B. cinerea shows resistance against the oxidative burst induced as a plant-host defense response, protecting itself with an extracellular catalase activity [44]. Beyond survival to an oxidative environment during plant-pathogen interaction, B. cinerea also stimulates ROS production in the plant. Early production of ROS and host cell death are indicative of a successful infection by B. cinerea [45]. In some plant-pathogen interactions, PCD promotes pathogen growth, especially those pathogens that secret toxins to the host cells [46]. ROS increase in Arabidopsis enhances necrosis induced by $B$. cinerea and this necrosis is dependent on host-activated HR and not 
by fungus toxicity, since $d n d 1$, a mutant with HR-deficiency is asymptomatic in response to $B$. cinerea infection [47]. Moreover, B. cinerea growth is fostered by ROS generation and HR establishment. The oxidative burst is effective to contend with biotrophic pathogens, but it is unable to protect the host against necrotrophs [48]. The above results demonstrated a correlation between ROS and lesion formation in response to $B$. cinerea infection in tomato plants, as was previously reported in Arabidopsis [47]. Massive necrosis was observed in plants infected with B. cinerea without T. asperellum pre-treatment. Under this condition, Botrytis lesion formation increased two-fold as compared to plants pretreated with T. asperellum. Regarding $\mathrm{H}_{2} \mathrm{O}_{2}$ production, this was suppressed at all times as evaluated by $T$. asperellum pretreatment suggesting that the biocontrol agent promoted resistance by inhibiting ROS formation and HR-like lesions.

A possible explanation for the mechanism by which Trichoderma spp mediates resistance in response to F. oxysporum and B. cinerea is through JA involvement, since this hormone controls fungi proliferation, up-regulates the expression of defense genes, induces the activities of catalase and ascorbate peroxidase and shows minimal lipid peroxidation and cell death after a challenge infection with these pathogens. Further research is required to elucidate the JA participation in the resistance induced by Trichoderma spp.

\section{Materials and Methods}

\subsection{Plant Material}

Lycopersicon esculentum genotype Vita was used in the experiments. Seeds were surface-sterilized in $0.5 \%$ sodium hypoclorite for $5 \mathrm{~min}$, and rinsed twice with sterile water for $10 \mathrm{~min}$ before use. Seeds were germinated on 200-cavity trays with sterile peat moss and perlite (agrolite). Seedlings were grown in a greenhouse under $14 \mathrm{~h}$ light and 10 dark photoperiod at $27^{\circ} \mathrm{C}$ and $12{ }^{\circ} \mathrm{C}$, respectively.

\subsection{Trichoderma Inoculum Preparation}

The bio-agent was obtained from Dr. Hernández at Centro de Biotecnología Genómica (IPN), México. A pure culture of T. asperellum was maintained on PDA plates at $25^{\circ} \mathrm{C}$ for 7 days. For inoculum preparation, a solid formulation $(20 \mathrm{~g}$ of oat, $50 \mathrm{~mL}$ of kaolin, $100 \mathrm{~mL}$ of vermiculite and $60 \mathrm{~mL}$ of water (modified from Martínez-Medina et al. [31]) was sterilized and the substrate was later inoculated with T. asperellum $\left(1 \times 10^{5}\right.$ spores $\left.\mathrm{mL}^{-1}\right)$ under sterile conditions and incubated for one week at $28^{\circ} \mathrm{C}$.

\subsection{Inoculation of Tomato Plants with T. Asperellum}

After complete plant emergence at 2 weeks, individual seedlings were thinned out to 6-inch pots containing commercial peat moss and vermiculite $(7: 3, v / v)$ supplemented with a mixture containing the solid substrate previously inoculated with T. asperellum or mock. Plants were returned to the green house.

\subsection{Quantification of T. Asperellum in Growing Media}

To quantify T. asperellum in the growing media, one gram of soil mixture containing the solid substrate inoculated with T. asperellum or mock was plated on potato dextrose agar (PDA) supplemented with $50 \mathrm{mg} \mathrm{L}^{-1}$ rose bengal and $10 \%$ streptomycin sulphate [31]. Medium was $\mathrm{pH} 4.9$ adjusted with lactic acid. Plates were incubated at $28^{\circ} \mathrm{C}$ for 5 days and then colony-forming units (CFUs) were counted. Data were expressed as Log CFU per gram of dry substrate.

\subsection{Evaluation of Tomato Plant in Growing Media Inoculated with T. Asperellum}

Plant Absolute Growth Rate (AGR) was evaluated forty days after inoculation with. T asperellum by recording shoot height. AGR was calculated using the formula AGR $=(\mathrm{H} 2-\mathrm{H} 1) /(\mathrm{t} 2-\mathrm{t} 1)$ [49]. Leaf area $\left(\mathrm{cm}^{2}\right)$, chlorophyll content, fresh weight $(\mathrm{g})$ and dry weight $(\mathrm{g})$ were also evaluated at 40 days post inoculation. For leaf area, individual leaves of tomato plants were scanned and subsequently 
analyzed by Image J 1.44 [50]. Optical measurements were made on leaves of 10 plants using a SPAD-502Plus (Konica Minolta Sensing, Inc., Tokyo, Japan). Fresh and dry weight were measured with a precision analytical balance. All measurements were recorded for at least 10 plants per treatment with three independent repetitions.

\subsection{Isolation and Identification of Fungal Pathogens}

A Fusarium strain was isolated from rotted tomato (cv. Saladette) roots by placing the disinfected tissue on PDA plates and incubating for 7 days. The mycelia emerging from the tissue was transferred to a fresh PDA plate and a mycelial plug from this plate was resuspended in sterile water. Serial dilutions from these spore suspensions were performed and a $100-\mu \mathrm{L}$ aliquot of a 100 -fold dilution was plated on $1 \%$ agar and incubated for $24-48 \mathrm{~h}$. Single-conidia germinating were transferred to PDA plates and an agar plug from these cultures was used to inoculate GYAM liquid media. The mycelial mat from 5-day-old culture was used to extract genomic DNA. The PCR reaction was performed for 30 cycles using the ef1 (forward primer: $5^{\prime}$-ATGGGTAAGGA(A/G)GACAAGAC-3') and ef2 (reverse primer: $5^{\prime}$-GGA(G/A)GTACCAGT(G/C)ATCATGTT-3') with an annealing temperature of $53{ }^{\circ} \mathrm{C}$. The 700-bp amplicon was gel-purified and used for DNA sequencing with the ef 22 internal reverse primer (5'-AGGAACCCTTACCGAGCTC-3'), according to Geiser et al. [51]. The 350-bp sequence was analyzed through the Fusarium ID platform (http://isolate.fusariumdb.org/) for species identification.

B. cinerea was isolated on PDA media from tomato fruits showing typical signs of grey mould. Plates were incubated at $22{ }^{\circ} \mathrm{C}$ with $14 \mathrm{~h}$ darkness and $10 \mathrm{~h}$ light for 7 days. Pathogenicity tests were performed following Koch's postulates.

\subsection{Evaluation of Effectiveness of T. asperellum against Fungal Pathogens in Tomato Plants}

Roots of plants grown for 3 weeks in media with and without $T$. asperellum formulation were cut about $1 \mathrm{~cm}$ from the tips, and the roots were placed during $5 \mathrm{~min}$ in the F. oxysporum suspension $\left(1 \times 10^{5}\right.$ conidia $\left.\mathrm{mL}^{-1}\right)$. Control plants were mock-inoculated with sterile distilled water. Disease progression was followed through photograph records of symptoms 3 weeks post-inoculation (wpi). Plant fresh weight was recorded at 1 and 3 wpi.

Disease severity was calculated by the number of leaves showing different levels of wilt symptom and expressed as percentage in reference of total number of leaves per plant. Symptoms were recorded at 1 and 3 wpi. Phenotypic analysis, disease severity and loss weight assays were repeated three times with 10 replicates per treatment.

To explore disease progression, a colonization assay was performed in non- and pretreated plants with T. asperellum for 3 weeks and infected with F. oxysporum for 3 weeks.

Stem sections were collected from cotyledon node, first and second nodes. Sections were surface sterilized in $70 \%$ ethanol and rinsed in sterile distilled water and placed on PDA supplemented with $200 \mathrm{mg} / \mathrm{mL}$ streptomycin at $25^{\circ} \mathrm{C}$. Photographs were taken after 5 days of incubation on PDA. The experiment was repeated three times.

The B. cinerea strain was routinely cultivated in Petri dishes containing PDA. For inoculation, detached leaves from 5-week-old plants were laid on Petri dishes containing two blotting filter papers (Whatman) wetted with sterile water, then spotted with 5-mm-diameter agar plugs containing growing hyphae from $B$. cinerea [52]. Lesions were measured using the ImageJ software employing a calibration scale [50] at 1 and 2 wpi. Experiments were repeated three times with 10 replicates per treatment.

\subsection{Evaluation of T. asperellum Effect on $\mathrm{H}_{2} \mathrm{O}_{2}$ Production in Tomato Fungal-Infected Plants}

DAB is taken up by living plant tissue and can be used to show $\mathrm{H}_{2} \mathrm{O}_{2}$ production when peroxidase activity is present [53]. Detection of hydrogen peroxide was conducted using 3,3'-diaminobenzidine (DAB) from Sigma-Aldrich. Leaves were infected with F. oxysporum or B. cinerea, respectively and collected at different times. Plant tissues were immersed with $1 \mathrm{~mL}$ of DAB liquid buffer solution for $2 \mathrm{~h}$. After staining, the tissues were fixed in ethanol:glycerol:acetic acid 3:1:1 (v:v:v) (bleaching 
solution) placed in a water bath at $95^{\circ} \mathrm{C}$ for $15 \mathrm{~min}$. Leaves were reimmersed in bleaching solution until chlorophyll was completely depleted.

\subsection{Statistical Analyses}

Data on AGR, leaf areas, SPAD units, fresh and dry weight and disease severity were subjected to a pairwise comparison with Student's $t$-test $(p<0.05)$ implemented in Excel software.

\section{Conclusions}

This study demonstrates the successful use of a solid formulation based in kaolin as inoculum with $T$. asperellum to enhance tomato plants growth and defense against pathogens. The fact that T. asperellum inhibits ROS accumulation makes it an excellent candidate to control fungal pathogens that promote oxidative stress as mechanism for successful disease establishment. The application of this bioformulation can have a positive impact on disease management in sustainable agriculture. The effective application of the bioformulation in the field requires more research on issues such as shelf life of the product and its viability during storage.

Author Contributions: Conceptualization, M.S.-G.; Results and Method development: V.I.H.-T., A.K.C.-O. and J.P.; Writing—original draft, M.S.-G.; Writing—review \& editing, M.G.-R., J.P., O.A.-C., S.H.-L. All authors read and approved the final manuscript.

Funding: This work was supported by grants from Consejo Nacional de Ciencia y Tecnología (CONACyT) (255265), Mexico. V.I.H.-T., A.K.C.-O., A.V.A., L.H.N.L. and J.M.I.B. received CONACyT $(25647,25641,28143$, 28192, 28137, respectively) fellowships.

Acknowledgments: We thank A. Vargas Almendra, LH Naranjo Luna and JM Ibarra Mayen for technical assistance. We appreciate the T. asperellum strain donation from Sobeida Sánchez Nieto and Hernández (Centro de Biotecnología Genómica, IPN, México).

Conflicts of Interest: The authors declare no conflict of interest.

\section{References}

1. Kubicek, C.P.; Harman, G.E. Trichoderma and Gliocladium: Basic Biology, Taxonomy and Genetics; Taylor \& Francis: London, UK, 1998; Volume 1.

2. Mohiddin, F.A.; Khan, M.R.; Khan, S.M.; Bhat, B.H. Why Trichoderma is considered super hero (super fungus) against the evil parasites? Plant. Pathol. J. 2010, 9, 92-102. [CrossRef]

3. Harman, G.E. Overview of mechanisms and uses of Trichoderma spp. Phytopathology 2006, 96, 190-194. [CrossRef]

4. Woo, S.L.; Lorito, M. Exploiting the interactions between fungal antagonists, pathogens and the plant for biocontrol. In Novel Biotechnologies for Biocontrol Agent Enhancement and Management; Vurro, M., Gressel, J., Eds.; NATO Security through Science Series; Springer: Dordrecht, The Netherlands, 2006; pp. 107-130. [CrossRef]

5. Hermosa, R.; Rubio, M.B.; Cardoza, R.E.; Nicolás, C.; Monte, E.; Gutiérrez, S. The contribution of Trichoderma to balancing the costs of plant growth and defense. Int. Microbiol. 2013, 16, 69-80. [CrossRef] [PubMed]

6. Benítez, T.; Rincón, A.M.; Limón, M.C.; Codón, A.C. Biocontrol mechanisms of Trichoderma strains. Int. Microbiol. 2004, 7, 249-260. [CrossRef]

7. Bigirimana, J.; De Meyer, G.; Poppe, J.; Hoefte, M. Induction of systemic resistance on bean (Phaseolus vulgaris) by Trichoderma harzianum. Med. Fac. Landbouwwet. Univ. Gent. 1997, 62, 1001-1007.

8. Choudhary, D.K.; Prakash, A.; Johri, B.N. Induced systemic resistance (ISR) in plants: Mechanism of action. Indian J. Microbiol. 2007, 47, 289-297. [CrossRef] [PubMed]

9. Niki, T.; Mitsuhara, I.; Seo, S.; Ohtsubo, N.; Ohashi, Y. Antagonistic effect of salicylic acid and jasmonic acid on the expression of pathogenesis-related (PR) protein genes in wounded mature tobacco leaves. Plant Cell Physiol. 1998, 39, 500-507. [CrossRef]

10. Glazebrook, J. Contrasting mechanisms of defense against biotrophic and necrotrophic pathogens. Annu. Rev. Phytopathol. 2005, 43, 205-227. [CrossRef] 
11. Shoresh, M.; Harman, G.E.; Mastouri, F. Induced systemic resistance and plant responses to fungal biocontrol agents. Annu. Rev. Phytopathol. 2010, 48, 21-43. [CrossRef]

12. Bhattacharyya, S.K.; Basu, M.K. Kaolin powder as a fungal carrier. Appl. Environ. Microbiol. 1982, 44, 751-753.

13. Boyette, C.D.; Quimby, P.C., Jr.; Daigle, D.J.; Fulgham, F. Progress in the production formulation and application of mycoherbicides. In Microbial Control of Weeds; Tebbest, D., Ed.; Chapman and Hall: New York, NY, USA, 1991; pp. 209-222.

14. Shabana, Y.M.; Muller-Stover, D.; Sauerborn, J. Granular pesta formulation of Fusarium oxysporum f. sp orthoceras for biological control of sunflower broomrape: Efficacy and shelf-life. Biol. Control 2003, 26, 189-201. [CrossRef]

15. Kinay, P.; Yildiz, M. The shelf life and effectiveness of granular formulations of Metschnikowia pulcherrima and Pichia guilliermondii yeast isolates that control postharvest decay of citrus fruit. Biol. Control 2008, 1, 433-440. [CrossRef]

16. Patterson, S.H.; Murray, H.H. Clays. In Industrial Mineral and Rocks; Lefond, S.J., Ed.; Society of Mining Engineers: New York, NY, USA, 1983; Volume 1.

17. Connick, W.J.; Boyette, C.D.; Mc Alpine, J.R. Formulation of mycoherbicides using a pasta-like process. Biol. Control 1991, 1, 281-287. [CrossRef]

18. Boyette, C.D.; Walker, H.L. Evaluation of Fusarium lateritium as a biological herbicide for controlling velvetleaf (Abutilon theophrasti) and prickly sida (Sida spinosa). Weed Sci. 1986, 34, 106-109. [CrossRef]

19. Boyette, C.D.; Jackson, M.A.; Bryson, C.T.; Hoagland, R.E.; Connick, W.J., Jr.; Daigle, D.J. Sesbania exaltata biocontrol with Colletotrichum truncatum microsclerotia formulated in 'Pesta' granules. BioControl 2007, 52, 413-426. [CrossRef]

20. Adetunji, C.; Oloke, J. Efficacy of freshly prepared pesta granular formulations from the multi-combination of wild and mutant strain of Lasiodiplodia pseudotheobromae and Pseudomonas aeruginosa. Albanian J. Agric. Sci. 2013, 12, 555-563.

21. Zdor, R.E.; Alexander, C.M.; Kremer, R.J. Weed suppression by deleterious rhizobacteria is affected by formulation and soil properties. Commun. Soil Sci. Plant Anal. 2005, 36, 1289-1299. [CrossRef]

22. Mejri, D.; Gamalero, E.; Souissi, T. Formulation development of the deleterious rhizobacterium Pseudomonas trivialis X33d for biocontrol of brome (Bromus diandrus) in durum wheat. J. Appl. Microbiol. 2012, 114, 219-228. [CrossRef]

23. Connick, W.J.; Nickle, W.R.; Vinyard, B.T. "Pesta": New granular formulations for Steinernema carpocapsae. J. Nematol. 1993, 25, 198-203.

24. Rothan, C.; Diouf, I.; Causse, M. Trait discovery and editing in tomato. Plant J. 2019, 97, 73-90. [CrossRef]

25. Agrios, G.N. Plant Pathology, 5th ed.; Elsevier Academic Press: Burlington, MA, USA, 2005; ISBN 0-12-044565-4.

26. Martin, F.N. Development of alternative strategies for management of soilborne pathogens currently controlled with methyl bromide. Annu. Rev. Phytopathol. 2003, 41, 325-350. [CrossRef]

27. Mao, W.; Lewis, J.A.; Lumsden, R.D.; Hebbar, K.P. Biocontrol of selected soilborne diseases of tomato and pepper plants. Crop Prot. 1998, 17, 535-542. [CrossRef]

28. Elad, Y.; Williamson, B.; Tudzynski, P.; Delen, N. Botrytis spp. and diseases they cause in agricultural systems-An introduction. In Biology, Pathology and Control Botrytis; Elad, Y., Williamson, B., Tudzynski, P., Delen, N., Eds.; Springer: Dordrecht, The Netherlands, 2004.

29. Leroch, M.; Kretschmer, M.; Hahn, M. Fungicide resistance phenotypes of Botrytis cinerea isolates from commercial vineyards in South West Germany. J. Phytopathol. 2011, 159, 63-65. [CrossRef]

30. Williamson, B.; Tudzynski, B.; Tudzynski, P.; van Kan, J.A. Botrytis cinerea: The cause of grey mould disease. Mol. Plant Pathol. 2007, 8, 561-580. [CrossRef]

31. Martínez-Medina, A.; Roldán, A.; Pascual, J.A. Performance of a Trichoderma harzianum bentonite-vermiculite formulation against Fusarium wilt in seedling nursery melon plants. HortScience 2009, 44, 2025-2027. [CrossRef]

32. Martínez-Medina, A.; Fernández, I.; Sánchez-Guzmán, M.J.; Jung, S.C.; Pascual, J.A.; Pozo, M.J. Deciphering the hormonal signalling network behind the systemic resistance induced by Trichoderma harzianum in tomato. Front. Plant Sci. 2013, 4, 206. [CrossRef]

33. Singh, A.; Shahid, M.; Srivastava, M.; Pandey, S.; Sharma, A.; Kumar, V. Optimal physical parameters for growth of Trichoderma species at varying $\mathrm{pH}$, temperature and agitation. Virol. Mycol. 2014, 3, 127. [CrossRef] 
34. Di, X.; Gomila, J.; Takken, F.L.W. Involvement of salicylic acid, ethylene and jasmonic acid signalling pathways in the susceptibility of tomato to Fusarium oxysporum. Mol. Plant Pathol. 2017, 18, 1024-1035. [CrossRef]

35. Harman, G.E. Myths and dogmas of biocontrol changes in perceptions derived from research on Trichoderma harzianum T-22. Plant Dis. 2000, 84, 377-393. [CrossRef]

36. Harman, G.E.; Björkman, T.; Ondik, K.; Soresh, M. Changing paradigms on the mode of action and uses of Trichoderma spp. for biocontrol. Outlooks Pest Manag. 2008, 19, 24-29. [CrossRef]

37. Tchameni, S.N.; Sameza, M.L.; O'donovan, A.; Fokom, R.; Ngonkeu, E.L.M.; Nana, L.W.; Etoa, F.X.; Nwaga, D. Antagonism of Trichoderma asperellum against Phytophthora megakarya and its potential to promote cacao growth and induce biochemical defence. Mycology 2017, 8, 84-92. [CrossRef]

38. Jogaiah, S.; Abdelrahman, M.; Tran, L.P.; Ito, S.I. Different mechanisms of Trichoderma virens-mediated resistance in tomato against Fusarium wilt involve the jasmonic and salicylic acid pathways. Mol. Plant Pathol. 2018, 19, 870-882. [CrossRef]

39. Ighodaroab, O.M.; Akinloye, O.A. First line defence antioxidants-superoxide dismutase (SOD), catalase (CAT) and glutathione peroxidase (GPX): Their fundamental role in the entire antioxidant defence grid. Alexandria J. Med. 2018, 54, 287-293. [CrossRef]

40. Zehra, A.; Meena, M.; Dubey, M.K.; Aamir, M.; Upadhyay, R.S. Synergistic effects of plant defense elicitors and Trichoderma harzianum on enhanced induction of antioxidant defense system in tomato against Fusarium wilt disease. Bot. Stud. 2017, 58, 44. [CrossRef]

41. Colmenares, A.J.; Aleu, J.; Durán-Patrón, R.; Collado, I.G.; Hernández-Galán, R. The putative role of botrydial and related metabolites in the infection mechanism of Botrytis cinerea. J. Chem. Ecol. 2002, 28, 997-1005. [CrossRef]

42. Reino, J.L.; Hernández-Galán, R.; Durán-Patrón, R.; Collado, I.G. Virulence-toxin production relationship in isolates of the plant pathogenic fungus Botrytis cinerea. J. Phytopathol. 2004, 152, 563-566. [CrossRef]

43. Choquer, M.; Fournier, E.; Kunz, C.; Levis, C.; Pradier, J.M.; Simon, A.; Viaud, M. Botrytis cinerea virulence factors: New insights into a necrotrophic and polyphageous pathogen. FEMS Microbiol. Lett. 2007, 277, 1-10. [CrossRef]

44. Schouten, A.; Tenberge, K.B.; Vermeer, J.; Stewart, J.; Wagemakers, L.; Williamson, B.; van Kan, J.A. Functional analysis of an extracellular catalase of Botrytis cinerea. Mol. Plant Pathol. 2002, 3, 227-238. [CrossRef]

45. Govrin, E.M.; Rachmilevitch, S.; Tiwari, B.S.; Solomon, M.; Levine, A. An elicitor from Botrytis cinerea induces the Hypersensitive Response in Arabidopsis thaliana and other plants and promotes the gray mold disease. Phytopathology 2006, 96, 299-307. [CrossRef]

46. Greenberg, J.T.; Yao, N. The role and regulation of programmed cell death in plant-pathogen interactions. Cell. Microbiol. 2004, 6, 201-211. [CrossRef]

47. Govrin, E.M.; Levine, A. The hypersensitive response facilitates plant infection by the necrotrophic pathogen Botrytis cinerea. Curr. Biol. 2000, 10, 751-757. [CrossRef]

48. Temme, N.; Tudzynski, P. Does Botrytis cinerea ignore $\mathrm{H}_{2} \mathrm{O}_{2}$-induced oxidative stress during infection? Characterization of Botrytis activator protein 1. Mol. Plant Microbe. Interact. 2009, 22, 987-998. [CrossRef]

49. Redford, P.J. Growth analysis formulae their use and abuse. Crop. Sci. 1967, 7, 171-175. [CrossRef]

50. Schneider, C.A.; Rasband, W.S.; Eliceiri, K.W. NIH image to imagej: 25 years of image analysis. Nat. Methods 2012, 9, 671-675. [CrossRef]

51. Geiser, D.M.; Jiménez-Gasco, M.M.; Kang, S.; Makalowska, I.; Veeraraghavan, N.; Ward, T.J.; Zhang, N.; Kuldau, G.A.; O’Donnell, K. Fusarium-ID v.10: A DNA sequence database for identifying Fusarium. Eur. J. Plant Pathol. 2004, 110, 473-479. [CrossRef]

52. El Oirdi, M.; Bouarab, K. Plant signalling components EDS1 and SGT1 enhance disease caused by the necrotrophic pathogen Botrytis cinerea. New Phytol. 2007, 175, 131-139. [CrossRef] [PubMed]

53. Thordal-Christensen, H.; Zhang, Z.; Wei, Y.; Collinge, D.B. Subcellular localization of $\mathrm{H}_{2} \mathrm{O}_{2}$ in plants. $\mathrm{H}_{2} \mathrm{O}_{2}$ accumulation in papillae and hypersensitive response during the barley-powdery mildew interaction. Plant J. 1997, 11, 1187-1194. [CrossRef]

(C) 2019 by the authors. Licensee MDPI, Basel, Switzerland. This article is an open access article distributed under the terms and conditions of the Creative Commons Attribution (CC BY) license (http://creativecommons.org/licenses/by/4.0/). 